\title{
Composição química e digestibilidade 'in vitro’ de silagens de milho com distintos teores de umidade e níveis de compactação
}

\author{
Chemical composition and 'in vitro' digestibility of maize silages with different \\ maturities and packing densities \\ Clóvis Clenio Diesel Senger ${ }^{1}$ Paulo Roberto Frenzel Mühlbach ${ }^{2}$ \\ Luis Maria Bonnecarrère Sánchez ${ }^{3}$ Diego Peres Netto ${ }^{4}$ Lisiane Dorneles de Lima ${ }^{4}$
}

RESUMO

Foi avaliada a composição química $e$ a digestibilidade 'in vitro' de silagens de milho e respectivas forragens frescas, colhidas com três teores de MS (20, 26 e $28 \%)$ e submetidas antes da ensilagem, a duas compactações (bem compactadas ' $B C$ ', ou mal compactadas ' $M C$ '), formando um fatorial $3 \times 2$ com seis repetições num experimento com micro-silos. Foi realizado o fracionamento dos glicídios e da proteína nas silagens, para determinar componentes que podem ser usados nos modelos mecanicistas de predição de consumo e desempenho animal. Apenas o tratamento com o material mais úmido e bem compactado produziu efluente na quantidade de $61,2 \mathrm{ton}^{-1}$. A DIVMS variou entre 46,2 e 57,9\%, aumentando significativamente com o aumento da MS, enquanto que a DIVMO variou entre 44,5 e $54,2 \%$, sendo significativamente menor apenas nos tratamentos com $20 \%$ MS. Os valores de proteína bruta solúvel (PBSol) variaram entre 44,8 e 54,3\% da PB. O NNP variou entre 67 e 91\% da PBSol, enquanto que a PIDN ficou entre 16,2 e $25,1 \%$ da PB total. A PIDA variou entre 6,7 e $12,8 \%$ da $P B$ total sendo que os maiores valores foram encontrados na silagem mais úmida. A fração A dos glicídios variou entre 5,3 e 10\% da MS, sendo superior na silagem bem compactada com 28\% MS. A fração B1 oscilou entre 13,1 e $25,8 \%$ da MS aumentando significativamente das silagens mais úmidas para as mais secas. A fração B2 apresentou médias entre 40,2 e $50,3 \%$, diminuindo significativamente das silagens mais úmidas para as mais secas. A fração $C$ variou entre $8,8 e$ $11,9 \%$ na MS. Em relação às forragens frescas de origem, observou-se aumento substancial nas frações protéicas PIDA e PBSol, diminuição na PIDN, e valores similares no NNP expresso como \% da PBSol, exceto no tratamento 20BC. Nos glicídios houve diminuição da fração $A$ em todos os tratamentos (exceto em 28BC), aumento na fração B1 nos tratamentos 26 e $28 \%$ MS e valores similares no tratamento $20 \%$ MS, ocorrendo o inverso na fração B2. A fração C aumentou apenas nos tratamentos com 28\% MS. Não houve variação significativa tanto na DIVMS quanto na DIVMO das silagens em relação à forragem fresca.

Palavras-chave: frações glicídicas, frações protéicas, densidade, matéria seca ao corte.

\section{ABSTRACT}

An experiment was carried out to evaluate the chemical composition and 'in vitro' digestibility of maize silages and their respective original materials, harvested at three maturities (20, 26 and 28\% DM), and ensiled with high or low packing density in a $3 \times 2$ factorial arrangement with six replicates. Protein and carbohydrate fractions were determined to supply mechanistic models of intake and performance predictions. Effluent was produced (61,2 liters ton $^{-1}$ ) only in treatment with higher moisture and higher packing density. IVDMD varied from 46,2 to $57,9 \%$, and increased significantly with increasing DM level. IVOMD (44,5 - 54,2\%) was smaller only in $20 \%$ DM silages. Soluble crude protein (SCP) ranged between $44,8-54,3 \%$ of crude protein (CP), and NPN reached $67-91 \%$ of SCP. NDIP was 16,2 $25,1 \%$ of $C P$ and ADIP varied between $6,7-12,8 \%$ of $C P$. The higher values of ADIP were obtained in silages with lower DM. Fraction A of carbohydrates varied between 5,3-10\% $D M$ being significantly higher in 28\% DM silage with higher packing. B1 fraction $(13,1-25,8 \%$ DM) increased significantly with increasing DM content. B2 fraction (40,2 -

\footnotetext{
${ }^{1}$ Laboratório de Nutrição Animal, Departamento de Zootecnia, Universidade Federal de Santa Maria (UFSM), 97105-900, Santa Maria, RS, Brasil. E-mail: clovisdiesel@smail.ufsm.br

${ }^{2}$ Departamento de Zootecnia, UFRGS, Porto Alegre, RS, Brasil.

${ }^{3}$ Departamento de Zootecnia, UFSM, Santa Maria, RS, Brasil.

${ }^{4}$ Programa de Pós-graduação em Zootecnia, UFSM, Santa Maria, RS, Brasil.
} 
$50,3 \%$ DM) and were not affected with increasing DM content. Fraction $C$ varied from 8,8 to $11,9 \%$ DM. When silages were compared with original forages, an increasing level of ADIP and SCP, a decreasing level of NDIP and similar values for $N P N$ as a percentage of SCP were observed, except in high packed 20\% DM silage. Within the carbohydrates fraction a decrease in fraction A content was observed for all treatments, except for the 28\% DM high packing density silage. An increasing level in B1 fraction in 26 and 28\% DM treatments, and similar values in 20\% DM were observed. The opposite was observed in $B 2$ fraction. Fraction $C$ increased only in $28 \%$ DM treatments. No differences in IVDMD and IVOMD of silages were observed in relation to the original materials.

Key words: carbohydrate fractions, protein fractions, density, dry matter at harvest.

\section{INTRODUÇÃO}

A alimentação representa, em geral, o maior custo na produção animal. O principal componente das dietas normalmente oferecidas aos ruminantes é o volumoso, e é reconhecido que a sua composição química e valor nutricional é amplamente variável, dependendo de vários fatores como o tipo, espécie e variedade da planta forrageira, tipo e grau de processamento e armazenamento, clima, maturidade, entre outros.

A análise química dos alimentos freqüentemente tem custo elevado. No entanto, ela pode fornecer importante informação sobre os fatores que podem limitar o desempenho animal. Os métodos de caracterização química não fornecem uma estimativa direta do valor nutritivo, porém quando associados estatisticamente, podem ser utilizados para, juntamente com o uso de modelos, predizer o desempenho animal (CHERNEY, 2000).

A base para o recente desenvolvimento de sistemas nutricionais mecanísticos, como o NRC (2001) e o Cornell Net Carbohydrate and Protein System (CNCPS 2003), os quais têm maior potencial de análise da condição nutricional dos sistemas de produção de ruminantes, foi proporcionada por SNIFFEN et al. (1992). No entanto, estes sistemas exigem entre outros, a quantificação das frações que compõem a proteína e os carboidratos dos alimentos em função das suas características de degradação no trato digestivo dos animais.

Em função da enorme carência de dados obtidos no Brasil sobre o valor energético dos alimentos, bem como sobre o fracionamento mínimo de proteína e carboidratos, tem sido sugerido (VALADARES FILHO, 2000), que sejam conduzidas mais pesquisas nesta área, buscando predizer com maior eficiência o consumo e o desempenho animal a partir do conhecimento adequado da composição dos alimentos.

Por outro lado, a utilização de silagens na formulação de dietas, especialmente para gado leiteiro de média à alta produção, vem experimentando um crescimento nos últimos anos no Brasil.

O principal fator que determina o valor nutritivo da silagem de milho é o estágio de maturação ao corte (JOHNSON et al., 1999). Entretanto, a preservação da qualidade da planta de milho por ocasião do seu processo de ensilagem depende ainda de mecanismos críticos para limitar os processos de respiração da planta após o corte, da atividade proteolítica, da atividade de bactérias do gênero Clostridium e do crescimento de microorganismos aeróbios (MUCK, 1988).

A atividade das enzimas proteolíticas pode diminuir o valor nutritivo de um alimento ensilado através da transformação do nitrogênio protéico em formas de NNP, como peptídeos e aminoácidos livres. Isto permite que bactérias proteolíticas fermentem estes peptídeos e aminoácidos, transformando-os em uma variedade de ácidos orgânicos, $\mathrm{CO}_{2}$, amônia e aminas, produtos estes ligados à redução de consumo voluntário das silagens pelos animais (MULLIGAN et al., 2002). VAN SOEST (1994) afirma que as perdas em energia do alimento através do processo de ensilagem ocorrem de diferentes maneiras: através da respiração inicial das plantas, da fermentação anaeróbica, da decomposição aeróbica e da perda por efluentes, especialmente em materiais com alta umidade ensilados diretamente.

Em função disso, o material deve ser compactado e o silo fechado no menor espaço de tempo possível, mantendo-se as condições anaeróbias a fim de que as características qualitativas do material removido do silo sejam bastante similares àquele de origem.

A qualidade final da silagem é dependente das concentrações de glicídios estruturais e não estruturais e da relação entre os mesmos. Deve-se buscar o máximo de preservação desses últimos e da proteína verdadeira, já que isto irá influenciar o volume de concentrados na dieta dos animais.

Assim, este trabalho objetivou avaliar os efeitos dos fatores "teor de matéria seca ao corte” e "compactação" de silagens de milho sobre a composição química, especialmente sobre a fração dos glicídios não estruturais bem como sobre a digestibilidade ‘in vitro’ das mesmas.

\section{MATERIAL E MÉTODOS}

O trabalho foi desenvolvido na Universidade Federal de Santa Maria (UFSM). Para a 
obtenção das silagens de milho, foi utilizado o híbrido comercial Ag 5011, colhido com três teores de matéria seca (MS). Os tratamentos foram distribuídos em um delineamento experimental inteiramente casualizado com seis repetições em um esquema fatorial três $\mathrm{x}$ dois (três teores de MS, 20, 26 e 28\%, e dois métodos de ensilagem, bem compactado 'BC' e mal compactado 'MC', determinados pela densidade), de acordo com o seguinte modelo matemático:

Yijk $=\mu+$ ái + âj + áâij + åijk , onde:

$\mu=$ média geral da variável em estudo; ai = efeito do i-ésimo nível de MS(i=20, 26 e 28\% MS); ßj = efeito do j-ésimo nível de compactação; aâij =efeito da interacão entre o i-ésimo nível de a e o j-ésimo nível de ß; e åijk = erro aleatório associado à observação Yijk. Foi realizada análise de variância e comparação das médias pelo teste de Tukey em nível de 5\% de significância.

Foram confeccionados micro-silos em sacos plásticos duplos, sobrepostos, marcados no volume de vinte litros, compactados manualmente com um socador de madeira. Em cada corte, metade do material picado com partícula aproximada de $2 \mathrm{~cm}$, foi imediatamente colocado nos sacos, compactado e vedado caracterizando o procedimento de ensilagem rápida, constituindo os tratamentos 'bem compactado' (BC). A outra metade foi colocada em sacos porosos (ráfia) por aproximadamente seis horas para permitir a continuidade da respiração, objetivando simular o que acontece em nível de propriedade, quando a planta picada permanece muitas vezes por longos períodos em contato com o ar antes de o silo ser completamente vedado. Após esse período, o material foi ensilado seguindo o procedimento descrito acima, constituindo os tratamentos 'mal compactado' (MC). A densidade obtida nos tratamentos, em $\mathrm{kg}$ de matéria verde $\mathrm{m}^{-3}$, foi a seguinte: $20 \mathrm{BC}=700 \mathrm{~kg} ; 20 \mathrm{MC}=400 \mathrm{~kg} ; 26 \mathrm{BC}=625 \mathrm{~kg}$; $26 \mathrm{MC}=350 \mathrm{~kg} ; 28 \mathrm{BC}=625 \mathrm{~kg}$ e $28 \mathrm{MC}=350 \mathrm{~kg}$.

A coleta de efluentes foi efetuada através de um pequeno orifício na parte inferior dos sacos, os quais eram imediatamente fechados para evitar a entrada de oxigênio no material. Os silos foram abertos após 90 dias, retirando-se amostras representativas para posterior análise.

Os teores de MS foram obtidos secandose a amostra a $55^{\circ} \mathrm{C}$ em estufa de ar forçado, sendo moída em peneira de $1 \mathrm{~mm}$, e posteriormente a $105^{\circ} \mathrm{C}$. As análises de $\mathrm{N}-\mathrm{NH}_{3}$ foram feitas por microdifusão na amostra úmida (VOIGT \& STEGER, 1967), titulandose a solução com $\mathrm{HCl}$ 0,01 N. As frações nitrogenadas foram obtidas nas amostras moídas após pré-secagem, (SNIFFEN et al., 1992), utilizando-se ácido tricloroacético (TCA) para a obtenção da fração A e tampão borato-fosfato para a fração B1. As frações B3 e $C$ foram obtidas determinando-se o nitrogênio no resíduo após extração com solução em detergente neutro e ácido, respectivamente, de acordo com VAN SOEST et al. (1991).

Os teores de FDN, FDA e lignina foram determinados segundo VAN SOEST et al. (1991). Os carboidratos não fibrosos (CNF) foram calculados por diferença usando a equação: 100 - (PB + (FDN - PB na $\mathrm{FDN})+\mathrm{EE}+\mathrm{CZ}$ ). Os níveis de extrato etéreo (EE) foram obtidos com éter etílico em aparelho Soxtherm e os de cinzas (CZ) pela queima da amostra a $600{ }^{\circ} \mathrm{C}$. O fracionamento dos glicídios solúveis obedeceu à metodologia descrita por HALL (2000), onde os açúcares (mono e oligossacarídeos) foram determinados por colorimetria após extração com etanol $80 \%$, sendo ainda determinados os teores de proteína bruta (PB) e matéria orgânica (MO) no resíduo insolúvel em etanol (RIE) 80\%, necessários para a obtenção dos valores de ácidos orgânicos (AORG), calculados pela seguinte equação: $\mathrm{AORG}=(\mathrm{MO}-$ PB) - (MO no RIE - PB no RIE) - EE - ATSE, onde: ATSE = Açúcares Totais Solúveis em Etanol. A fração A foi obtida pela soma de açúcares e AORG, e a fração B1, por diferença entre os CNF e a fração A. A fração C foi estimada multiplicando-se a lignina por 2,4 e a B2 pela equação: FDN - (PB na FDN) - fração C (CNCPS, 2003).

O ensaio de digestibilidade "in vitro" da matéria seca (DIVMS) e matéria orgânica (DIVMO), foi conduzido segundo TILLEY \& TERRY (1963) modificado por PIRES et al., (1979) com inóculo de quatro ovinos fistulados no rúmen, os quais recebiam feno de boa qualidade.

\section{RESULTADOS E DISCUSSÃO}

Neste trabalho, apenas o tratamento 20 BC produziu efluente na quantidade de 61,2 litros ton ${ }^{-1}$ de matéria verde, com $\mathrm{pH}$ de 3,1 , e com as seguintes concentrações de nutrientes: nitrogênio $=67,3$ ton $^{-1}$; açúcares $=1.966,6$ ton $^{-1}$ de matéria verde. Perdas de proteína, carboidratos e minerais podem ocorrer através do efluente de materiais ensilados com elevado teor de umidade, sendo que o volume é influenciado, principalmente, pelo conteúdo de MS e pelo grau de compactação, com produção total que pode variar entre 50 a 300 litros ton ${ }^{-1}$ de forragem (LOURES \& NUSSIO, 2002).

A composição bromatológica dos materiais antes e após o processo de ensilagem de cada corte, bem como a digestibilidade 'in vitro' desses materiais são apresentados na tabela 1. 
Tabela 1 - Caracterização química das amostras da forragem fresca e das silagens nos três cortes, e digestibilidade 'in vitro' da matéria seca (DIVMS) e da matéria orgânica (DIVMO) desses materiais.,

\begin{tabular}{|c|c|c|c|c|c|c|c|c|c|}
\hline \multirow{3}{*}{ Variáveis } & \multicolumn{3}{|c|}{$20 \% \mathrm{MS}$} & \multicolumn{3}{|c|}{$26 \% \mathrm{MS}$} & \multicolumn{3}{|c|}{$28 \% \mathrm{MS}$} \\
\hline & \multirow{2}{*}{$\begin{array}{c}\text { Forragem } \\
\text { Fresca }\end{array}$} & \multicolumn{2}{|c|}{ Silagens } & \multirow{2}{*}{$\begin{array}{c}\text { Forragem } \\
\text { Fresca }\end{array}$} & \multicolumn{2}{|c|}{ Silagens } & \multirow{2}{*}{$\begin{array}{c}\text { Forragem } \\
\text { Fresca }\end{array}$} & \multicolumn{2}{|c|}{ Silagens } \\
\hline & & $\mathrm{BC}$ & $\mathrm{MC}$ & & $\mathrm{BC}$ & $\mathrm{MC}$ & & $\mathrm{BC}$ & MC \\
\hline Compactação (kg MV m³) & & 700 & 400 & & 625 & 350 & & 625 & 350 \\
\hline MS & 19,3 & 19,8 & 19,2 & 25,9 & 25,8 & 26,2 & 30,0 & 27,8 & 28,2 \\
\hline PB na AIN* & 7,8 & $7,3^{\mathrm{a}}$ & $8,3^{\mathrm{a}}$ & 7,9 & $7,6^{\mathrm{a}}$ & $8,2^{\mathrm{a}}$ & 7,8 & $7,7^{\mathrm{a}}$ & $8,1^{\mathrm{a}}$ \\
\hline PB na APS* & 7,5 & 6,4 & 7,6 & 7,6 & 6,5 & 7,3 & 7,7 & 7,5 & 7,6 \\
\hline $\mathrm{N}-\mathrm{NH}^{3}$ (\% do $\mathrm{N}$ total) & 2,3 & $10,3^{\mathrm{ab}}$ & $11,9^{\mathrm{a}}$ & 1,7 & $9,1^{\mathrm{bc}}$ & $9,3^{\mathrm{bc}}$ & 1,9 & $7,4^{\mathrm{cd}}$ & $6,4^{\mathrm{d}}$ \\
\hline $\mathrm{pH}$ & 5,6 & $3,6^{\mathrm{b}}$ & $3,8^{\mathrm{a}}$ & 5,6 & $3,7^{\mathrm{b}}$ & $3,8^{\mathrm{a}}$ & 5,6 & $3,8^{\mathrm{a}}$ & $3,8^{\mathrm{a}}$ \\
\hline FDN* & 60,6 & $62,3^{\mathrm{a}}$ & $63,9^{\mathrm{a}}$ & 58,6 & $54,5^{b}$ & $54,3^{b}$ & 58,3 & $51,6^{\mathrm{b}}$ & $50,6^{\mathrm{b}}$ \\
\hline FDA* & 35,0 & $38,1^{\mathrm{a}}$ & $39,3^{\mathrm{a}}$ & 28,6 & $32,2^{\mathrm{b}}$ & $32,5^{b}$ & 25,2 & $28,0^{c}$ & $28,1^{c}$ \\
\hline Hemicelulose* & 25,6 & $24,2^{\mathrm{a}}$ & $24,6^{\mathrm{a}}$ & 30,0 & $22,3^{\mathrm{a}}$ & $21,8^{\mathrm{a}}$ & 33.1 & $23,6^{\mathrm{a}}$ & $22,5^{\mathrm{a}}$ \\
\hline $\mathrm{EE}^{*}$ & 2,3 & $4,3^{\mathrm{a}}$ & $3,0^{\mathrm{b}}$ & 2,8 & $4,7^{\mathrm{a}}$ & $4,8^{\mathrm{a}}$ & 2,8 & $4,4^{\mathrm{a}}$ & $4,5^{\mathrm{a}}$ \\
\hline $\mathrm{CNF}^{*}$ & 27,3 & $22,8^{c}$ & $20,9^{c}$ & 29,0 & $30,8^{\mathrm{ab}}$ & $28,8^{\mathrm{b}}$ & 30,4 & $32,6^{\mathrm{ab}}$ & $33,7^{\mathrm{a}}$ \\
\hline Açúcares* & 7,3 & $1,0^{\mathrm{b}}$ & $0,8^{\mathrm{b}}$ & 6,4 & $1,0^{\mathrm{b}}$ & $1,0^{\mathrm{b}}$ & 7,1 & $1,8^{\mathrm{a}}$ & $1,6^{\mathrm{a}}$ \\
\hline Ácidos Orgânicos* & 6,6 & $8,3^{\mathrm{a}}$ & $6,3^{\mathrm{ab}}$ & 4,7 & $6,2^{\mathrm{ab}}$ & $4,8^{\mathrm{b}}$ & 4,1 & $8,2^{\mathrm{a}}$ & $3,7^{\mathrm{b}}$ \\
\hline Relação FDN/CNF & 2.22 & 2.73 & 3.06 & 2.02 & 1.77 & 1.88 & 1.92 & 1.58 & 1.50 \\
\hline DIVMS & 44,7 & $47,2^{\mathrm{c}}$ & $46,2^{\mathrm{c}}$ & 50,1 & $52,2^{\mathrm{b}}$ & $52,0^{\mathrm{b}}$ & 52,8 & $55,6^{\mathrm{a}}$ & $57,9^{\mathrm{a}}$ \\
\hline DIVMO & 47,9 & $44,5^{\mathrm{b}}$ & $44,5^{b}$ & 47,7 & $50,4^{\mathrm{ab}}$ & $50,7^{\mathrm{ab}}$ & 51,1 & $54,2^{\mathrm{a}}$ & $53,6^{\mathrm{a}}$ \\
\hline
\end{tabular}

BC - Bem Compactado $\quad$ MC - Mal Compactado

APS - Amostra Parcialmente Seca N-NH3 - Nitrogênio amoniacal

* Resultados expressos como \% da MS

Médias seguidas de letras diferentes na mesma linha, diferem entre si pelo teste de Tukey em nível de 5\% de probabilidade de erro.
Os níveis de $\mathrm{N}-\mathrm{NH}_{3}$ como \% do $\mathrm{N}$ total foram significativamente afetados apenas pelos níveis de MS da silagem, sendo maiores nos tratamentos 20BC e MC e menores nos tratamentos 28BC e MC. Os resultados estão em acordo com MUCK (1988), para o qual a atividade bacteriana de degradação protéica está relacionada ao nível de MS, sendo tanto maior quanto menor for o mesmo. Ao todo variaram entre 6,4 e $11,9 \%$ do $\mathrm{N}$ total, sendo que a faixa de $5-7 \%$ é considerada normal em silagens com 30-40\% de MS. O tratamento com 28\% de MS apresentou níveis de N$\mathrm{NH}_{3}$ dentro desta faixa. Os demais mostraram valores superiores a esse limite. HUHTANEN et al. (2003), avaliando as relações entre as características da fermentação de silagens e a produção de leite (200 observações), encontraram efeito negativo significativo no conteúdo de gordura e proteína do leite com o aumento dos níveis de $\mathrm{N}-\mathrm{NH}_{3}$ e ácidos totais das silagens.

$\mathrm{O}$ pH foi significativamente influenciado pela compactação nos tratamentos com níveis mais baixos de MS (20 e 26\%), sendo maior nos materiais mal compactados. Essa diferença foi maior entre os tratamentos 20BC e 20MC, quando chegou a dois décimos. Os níveis de PB (expressos em base seca) obtidos na amostra 'in natura' (AIN) foram sempre superiores àqueles obtidos na amostra parcialmente seca (APS), evidenciando a perda de componentes voláteis (especialmente $\mathrm{N}-\mathrm{NH}_{3}$ ) por ocasião do processo de pré-secagem, com diferenças menos acentuadas nos tratamentos 28BC e MC em relação aos demais.

Os teores de FDN variaram entre 50,6 e 63,9\%, e diminuíram significativamente do nível mais alto de umidade em relação aos demais, o que ocorreu devido ao aumento nos teores de amido refletidos pelos valores de CNF. Os percentuais foram semelhantes àqueles descritos por DEAVILLE \& GIVENS (2001), DI MARCO et al. (2002) e pelo CNCPS (2003). O pequeno aumento na FDN das silagens com $20 \%$ MS, em relação à forragem fresca, deve-se possivelmente à perda de açúcares solúveis causando um aumento dos carboidratos fibrosos. Nos demais tratamentos, a diminuição da FDN do material ensilado, em relação à forragem fresca, deve-se à diminuição dos níveis de hemicelulose nestes tratamentos. Segundo MÜHLBACH (2003), o teor de FDN de uma planta forrageira consolidou-se como o componente bromatológico melhor relacionado com o seu potencial de ingestão pelo ruminante. 
Na prática, a estimativa de consumo efetivo tem grande importância quando se busca determinar a quantidade de concentrado à suplementar, com o objetivo de controlar os custos da alimentação, além de evitar problemas de acidose (níveis de FDN $<28 \%$ na dieta) ou acetonemia (FDN > 35\% na MS da dieta), especialmente em vacas de alta produção leiteira. Os níveis de FDN encontrados neste trabalho são similares a outros trabalhos desenvolvidos no Brasil. FONTANELLI et al. (2000) encontraram valores médios de $60,7 \%$ em 246 silagens de milho oriundas de diferentes regiões do RS, enquanto COSTA et al. (2000) citam valores que variaram entre 52,1 e 59,5\% para o híbrido Ag 5011, utilizado no presente trabalho. O NRC (2001), no entanto, apresenta um teor médio de $45 \%$ de FDN em 1033 amostras de silagem de milho analisadas nos EUA. Para MÜHLBACH (2003), estas diferenças podem ser atribuídas ao maior teor intrínseco de FDN dos híbridos de origem tropical e, provavelmente, às técnicas inadequadas de ensilagem vigentes em nosso meio, o que leva a uma maior perda de açúcares solúveis, aumentando proporcionalmente o teor de FDN.

Os valores de FDA diminuíram significativamente com o aumento da MS das silagens, e foram semelhantes aos obtidos por DI MARCO et al. (2002) em silagens com 20, 26 e 32\% de MS.

Considerando-se que, aproximadamente, $70 \%$ da dieta de vacas leiteiras é constituída por carboidratos, esta fração do alimento merece especial atenção, em função do seu alto impacto sobre os custos de produção e efeito sobre a composição do leite. Do ponto de vista nutricional, é interessante verificar a relação FDN/CNF das forragens, a qual pode ser encontrada na tabela 1 . Observa-se que esta relação foi duas vezes maior no tratamento 20MC em relação aos tratamentos com $28 \%$ de MS. Com altas relações FDN/CNF, predominam os carboidratos que requerem sistemas enzimáticos de lenta digestão, com maior efeito de enchimento no rúmen, características que se refletem no consumo, como foi observado por MULLIGAN et al. (2002).

Os níveis de extrato etéreo mostraram-se sensíveis aos efeitos da compactação apenas no tratamento com menor teor de umidade, sendo significativamente mais baixos no material mal compactado, refletindo provavelmente maior concentração de AGV's e menor teor de ácido láctico.

Os CNF aumentaram significativamente com o aumento do teor de MS das amostras, concordando com outros trabalhos (DEAVILLE \& GIVENS 2001 e DI MARCO et al. 2002), e não foram significativamente afetados pela compactação.
Um acréscimo de 5,8g na produção diária de leite e de $0,03 \mathrm{~g}$ na gordura para cada $\mathrm{g} \mathrm{kg}^{-1}$ de MS de acréscimo nos níveis de carboidratos solúveis em água, foram observados por HUHTANEN et al. (2003). Justifica-se, portanto, o esforço em preservar o máximo desta fração nas silagens.

Não houve efeito da compactação sobre os níveis de açúcares solúveis, embora tenham sido observados teores significativamente mais elevados nas silagens com maior teor de MS. Os valores aproximam-se àqueles apresentados por HALL (2000), que sugere níveis entre 0,3 e 4,7\%, com média de $2 \%$ na MS. O teor estimado de ácidos orgânicos foi afetado de forma significativa pela compactação apenas no nível mais alto de MS, sendo menor no mal compactado. Isto pode ser atribuído em parte ao tipo esperado de fermentação nos diferentes tratamentos, com maior produção de ácido lático nos tratamentos bem compactados, o qual tem um menor coeficiente de volatilização (PORTER \& MURRAY, 2001), em relação a outros ácidos como acético e butírico. HALL (2000) cita valores médios de $8 \%$ de ácidos orgânicos em silagens.

A DIVMS aumentou significativamente dos níveis mais baixos de MS para os mais altos, enquanto que a DIVMO foi maior no nível mais alto de MS apenas em relação ao nível mais baixo. Esta técnica não foi suficientemente sensível para apontar diferenças entre a forragem fresca e o material ensilado.

Na tabela 2, são mostrados os valores das frações que compõem a proteína e os glicídios tanto na forragem fresca como no material ensilado. Os valores de proteína bruta solúvel (PBSol) variaram entre 44,8 e 54,3\% da $\mathrm{PB}$, e foram maiores que aqueles obtidos por MALAFAIA (1997) (32,7\% em silagem de milho com $28,8 \%$ de MS), e semelhantes àqueles descritos no CNCPS (2003), (41,4\%). Para a fração NNP, o CNCPS (2003) apresenta valores de 100\% em relação a PBSol, para todos os tipos de silagens de milho. Entretanto, neste trabalho foram observados percentuais que variaram entre 67,0 e 91,1 para esta fração, indicando a existência de valores entre 8,9 e 33,0\% de proteína verdadeira em relação à PB, na fração solúvel.

As variações na fração protéica associada à parede celular (PIDN) entre os tratamentos, aparentemente não se explicam de uma forma lógica. Sendo a silagem de milho um volumoso com baixo nível de proteína, esta variação pode estar associada ao erro experimental. A fração protéica, considerada indisponível (PIDA), não foi significativamente influenciada pela compactação, apenas pela umidade, sendo que os níveis mais altos foram observados nos 
Tabela 2 - Variáveis obtidas à partir do fracionamento da fração protéica e glicídica das silagens e da forragem fresca.

\begin{tabular}{|c|c|c|c|c|c|c|c|c|c|}
\hline \multirow{3}{*}{ Variáveis } & \multicolumn{3}{|c|}{$20 \% \mathrm{MS}$} & \multicolumn{3}{|c|}{$26 \% \mathrm{MS}$} & \multicolumn{3}{|c|}{$28 \% \mathrm{MS}$} \\
\hline & \multirow{2}{*}{$\begin{array}{c}\text { Forragem } \\
\text { Fresca }\end{array}$} & \multicolumn{2}{|c|}{ Silagens } & \multirow{2}{*}{$\begin{array}{c}\text { Forragem } \\
\text { Fresca }\end{array}$} & \multicolumn{2}{|c|}{ Silagens } & \multirow{2}{*}{$\begin{array}{c}\text { Forragem } \\
\text { Fresca }\end{array}$} & \multicolumn{2}{|c|}{ Silagens } \\
\hline & & $\mathrm{BC}$ & MC & & $\mathrm{BC}$ & MC & & $\mathrm{BC}$ & MC \\
\hline Compactação (kg MV m³ & & 700 & 400 & & 625 & 350 & & 625 & 350 \\
\hline MS & 19,3 & 19,8 & 19,2 & 25,9 & 25,8 & 26,2 & 30,0 & 27,8 & 28,2 \\
\hline PB na APS* & 7,5 & 6,4 & 7,6 & 7,6 & 6,5 & 7,3 & 7,7 & 7,5 & 7,6 \\
\hline \multicolumn{10}{|l|}{ Frações Protéicas } \\
\hline PB Sol (\% PB) & 32,0 & $44,8^{\mathrm{b}}$ & $50,2^{\mathrm{ab}}$ & 30,4 & $54,3^{\mathrm{a}}$ & $53,5^{\mathrm{a}}$ & 33,8 & $49,2^{\mathrm{ab}}$ & $45,0^{\mathrm{b}}$ \\
\hline NNP (\% PB Sol) & 94,9 & $67,0^{\mathrm{b}}$ & $77,1^{\mathrm{ab}}$ & 82,6 & $89,8^{\mathrm{a}}$ & $91,1^{\mathrm{a}}$ & 82,7 & $86,2^{\mathrm{a}}$ & $85,2^{\mathrm{a}}$ \\
\hline PIDN (\% PB) & 28,1 & $24,4^{\mathrm{ab}}$ & $25,1^{\mathrm{a}}$ & 28,4 & $21,1^{\mathrm{c}}$ & $16,2^{\mathrm{d}}$ & 38,1 & $16,4^{\mathrm{d}}$ & $21,8^{\mathrm{bc}}$ \\
\hline PIDA (\% PB) & 5,1 & $12,8^{\mathrm{a}}$ & $11,2^{\mathrm{ab}}$ & 5,4 & $9,2^{\mathrm{bc}}$ & $9,4^{\mathrm{bc}}$ & 4,4 & $7,9^{\mathrm{cd}}$ & $6,7^{\mathrm{d}}$ \\
\hline \multicolumn{10}{|l|}{ Frações glicídicas } \\
\hline Fração A* & 13,9 & $9,3^{\mathrm{a}}$ & $7,1^{\mathrm{ab}}$ & 11,2 & $7,2^{\mathrm{ab}}$ & $5,8^{\mathrm{b}}$ & 11,2 & $10,0^{\mathrm{a}}$ & $5,3^{\mathrm{b}}$ \\
\hline Fração B1* & 13,5 & $13,2^{\mathrm{c}}$ & $13,1^{\mathrm{c}}$ & 17,8 & $20,4^{\mathrm{b}}$ & $23,0^{\mathrm{ab}}$ & 19,2 & $22,6^{\mathrm{ab}}$ & $25,8^{\mathrm{a}}$ \\
\hline Fração B2* & 47,3 & $49,6^{\mathrm{a}}$ & $50,3^{\mathrm{a}}$ & 47,0 & $43,8^{\mathrm{b}}$ & $43,5^{\mathrm{b}}$ & 47,9 & $41,1^{\mathrm{b}}$ & $40,2^{\mathrm{b}}$ \\
\hline Fração C* & 10,9 & $11,2^{\mathrm{a}}$ & $11,9^{\mathrm{a}}$ & 9,2 & $9,4^{\mathrm{b}}$ & $9,7^{\mathrm{b}}$ & 7,3 & $9,3^{\mathrm{b}}$ & $8,8^{\mathrm{b}}$ \\
\hline
\end{tabular}

BC - Bem Compactado $\quad$ MC - Mal Compactado

* Resultados expressos como \% da MS

APS - Amostra Parcialmente Seca

PB - Proteína Bruta

Médias seguidas de letras diferentes, na mesma linha, diferem entre si pelo teste de Tukey em nível de 5\% de probabilidade de erro.

tratamentos com baixo teor de MS, diminuindo gradativamente com o aumento da MS. Nos tratamentos 28BC e MC os valores de PIDA de 7,9 e $6,7 \%$ da $\mathrm{PB}$, respectivamente, foram inferiores àqueles descritos por MALAFAIA (1997) e CNCPS (2003), que foram de 12,2 e $10,8 \%$, respectivamente.

A fração A dos glicídios, considerada total e prontamente degradada no rúmen, mostrou a mesma tendência dos ácidos orgânicos, visto que a mesma é obtida pela soma destes com os açúcares, sendo composta, no entanto, basicamente por ácidos, dada à pequena contribuição dos açúcares. Ressalta-se entretanto, que embora sejam pequenas as quantidades de açúcares envolvidos, estes foram significativamente maiores no material 28BC em relação aos demais, o que associado ao provável maior percentual de ácido láctico, neste tratamento, pode se traduzir em importante fonte rapidamente fermentável, proporcionando um melhor aproveitamento do $\mathrm{N}-\mathrm{NH}_{3}$ pela microflora ruminal, contribuindo de forma efetiva para uma melhor sincronia entre o aproveitamento dos nutrientes e a síntese microbiana ruminal (VAN SOEST, 1994).

A fração B1, que no caso de silagem de milho, é composta principalmente de amido, apresentou aumento significativo, partindo dos tratamentos 20BC e MC em relação aos demais, acompanhando a fração CNF, da qual a fração B1 é o principal componente. Estes valores encontram-se dentro da faixa média de 14-30 (\% da MS) de amido em silagens de milho apresentados por HALL (2000). O CNCPS (2003) descreve valores fixos de $80 \%$ de amido em relação aos CNF para silagens de milho com níveis de MS variando entre 25 e 35\%. Entretanto no presente trabalho, a fração B1 variou entre 57,9 \% no tratamento 20BC e 79,9\% no 26MC, em relação aos CNF. O fator compactação não teve efeito sobre a fração B1. Os níveis da fração B2 dos carboidratos, a qual apresenta taxa de degradação variável, porém mais lenta que a B1, foram maiores no tratamento com menor teor de MS em relação aos demais, acompanhando a FDN da qual ela é a principal componente. A fração C, que representa a porção não degradável e indigestível dos carboidratos, apresentou valores significativamente maiores no tratamento com menor teor de MS em relação aos demais, o que difere da bibliografia, que cita um aumento desta fração com o aumento do teor de matéria seca da silagem. Nenhuma das frações de carboidratos estruturais (B2 e C), sofreu efeito da compactação.

\section{CONCLUSÃO}

Silagens de milho muito úmidas produzem efluentes, os quais levam consigo nutrientes solúveis ( $\mathrm{N}$ e açúcares), e transformam uma parte maior do $\mathrm{N}$ em $\mathrm{N}$ indigestível. Por outro lado, silagens com maior teor MS e bem compactadas, preservam uma maior quantidade de açúcares que podem ser usados como fonte de energia pelos microorganismos ruminais. Além 
disto, silagens com maior teor de MS apresentam menor relação FDN/CNF e são mais digestíveis.

\section{AGRADECIMENTOS}

Parte do trabalho de tese de doutorado do primeiro autor, Universidade Federal do Rio Grande do Sul (UFRGS), RS Brasil.

\section{REFERÊNCIAS}

CHERNEY, D.J.R. Characterization of forages by chemical analysis. In: GIVENS D.I. et al. Forage evaluation in ruminant nutrition. London, UK: CABI, 2000. Cap.14, Sec 4, p.281-300.

CNCPS. Version 5.0. The net carbohydrate and protein system for evaluating herd nutrition and nutrient excretion, Model Documentation. Cornell: Cornell University, Department of Animal Science, 2003. 292p.

COSTA, R. de S. et al. Composição química da planta verde e das silagens de doze cultivares de milho. In: REUNIÃO ANUAL DA SOCIEDADE BRASILEIRA DE ZOOTECNIA, 37., 2000, Viçosa, MG. Anais... Viçosa: Sociedade Brasileira de Zootecnia, 2000. Forragicultura, 0376-CD.

DEAVILLE, D.R.; GIVENS, D.I. Use of the automated gas production technique to determine the fermentation kinetics of carbohydrate fractions in maize silage. Animal Feed Science and Technology, v.93, p.205-215, 2001.

DI MARCO, O.N. et al. Effect of maize crop maturity on silage chemical composition and digestibility (in vivo, in situ and in vitro). Animal Feed Science and Technology, v.99, p.37-43, 2002.

FONTANELI, R.S. et al. Avaliação da qualidade de silagens de milho através da espectrometria de reflectância no infravermelho proximal (NIRS). In: REUNIÃO ANUAL DA SOCIEDADE BRASILEIRA DE ZOOTECNIA, 37., 2000, Viçosa, MG. Anais... Viçosa: Sociedade Brasileira de Zootecnia, 2000. Forragicultura, 0748-CD.

HALL, M.B. Neutral detergent-soluble carbohydrates, nutritional relevance and analysis. A laboratory manual. Florida: University of Florida, 2000. 42p. (Bulletin 339).

HUHTANEN, P. et al. Relationships between silage fermentation characteristics and milk production parameters: analyses of literature data. Livestock Production Science v.81, p.57-73, 2003.

JOHNSON, L. et al. Nutritive value of corn silage as affected by maturity and mechanical processing: a contemporary review. Journal of Dairy Science, v.82, p.2813-2825, 1999.

LOURES, D.R.S.; NUSSIO, L.G. Produção de efluente em silagens úmidas. Capturado em 20 ago. 2002. Online. Disponível na Internet http://www.beefpoint.com.br/radares técnicos/conservação de forragens.
MALAFAIA, P.A.M. Taxas de digestão das frações protéicas e de carboidratos de alimentos por técnicas “in situ”, “in vitro" e de produção de gases. 1997. $85 \mathrm{f}$. Tese (Doutorado em Zootecnia) - Universidade Federal de Viçosa.

MUCK, R.E. Factors influencing silage quality and their implications for management. Journal of Dairy Science. v.71, p.2992-3002, 1988.

MÜHLBACH, P.R.F. Produção de leite com vacas de alta produtividade. In: REUNIÃO ANUAL DA SOCIEDADE BRASILEIRA DE ZOOTECNIA, 40., 2003, Simpósio Internacional de Ruminantes, Sessão Bovinocultura de Leite. Anais das Palestras... Santa Maria, RS: SBZ, 2003. 20p.

MULLIGAN, F.J. et al. Intake, digestibility, milk production and kinetics of digestion and passage for diets based on maize or grass silage fed to late lactation dairy cows. Livestock Production Science, v.74, p.113-124, 2002.

NRC - NATIONAL RESEARCH COUNCIL. Nutrient requirements of dairy cattle. 7rev.Ed. Washington, DC: National Academy of Science, 2001. 408p.

PORTER, M.G.; MURRAY, R.S. The volatility of components of grass silage on oven drying and the inter-relationship between dry-matter content estimated by different analytical methods. Grass and Forage Science, v.56, p.405-411, 2001.

PIRES, M.B.G. et al. Estabelecimento de um sistema de digestibilidade in vitro no laboratório da equipe de pesquisa em nutrição animal da Secretaria da Agricultura. Anuário Técnico do IPZFO, Porto Alegre, v.6, p.345-385, 1979.

SNIFFEN, C.J. et al. A net carbohydrate and protein system for evaluating cattle diets: Carbohydrate and protein availability. Journal of Animal Science, v.70, p.35623577, 1992.

TILLEY, J.M.; TERRY, R.A. A two-stage technique for the in vitro digestion of forage crops. Journal of British Grassland Society, v.18, p.104-111, 1963.

VALADARES FILHO, S. de C. Nutrição, avaliação de alimentos e tabelas de composição de alimentos para bovinos. In: REUNIÃO ANUAL DA SOCIEDADE BRASILEIRA DE ZOOTECNIA, 37., 2000, Viçosa. Anais das Palestras... Viçosa, MG: SBZ, 2000. Palestra 011-CD.

VAN SOEST, P.J. et al. Methods for dietary fiber, neutral detergent fiber, and nonstarch polysaccharide in relation to animal nutrition. Journal of Dairy Science, v.74, p.35833597, 1991.

VAN SOEST, P.J. Nutritional ecology of the ruminant. Ithaca: Cornell University, 1994. 476p.

VOIGT, J.; STEGER, H. Zur quantitativen Bestimmung von Ammoniak, Harnstoff and Ketokoerpern im biologischen Material. Archiv für Tierernährung, Berlin, v.17, p.289293, 1967. 